\title{
Chinese Medicine Outside of China
}

The Encounter between Chinese Medical Practices and Conventional Medicine in France and Italy

\section{Lucia Candelise}

Translator. Elizabeth Guill

\section{(2) OpenEdition}

12 Journals

Electronic version

URL: http://journals.openedition.org/chinaperspectives/5638

DOI: 10.4000/chinaperspectives.5638

ISSN: 1996-4617

\section{Publisher}

Centre d'étude français sur la Chine contemporaine

\section{Printed version}

Date of publication: 1 October 2011

Number of pages: $43-50$

ISSN: 2070-3449

\section{Electronic reference}

Lucia Candelise, "Chinese Medicine Outside of China », China Perspectives [Online], 2011/3 | 2011,

Online since 30 September 2014, connection on 28 October 2019. URL : http://

journals.openedition.org/chinaperspectives/5638; DOI : 10.4000/chinaperspectives.5638 


\title{
Chinese Medicine Outside of China
}

\author{
The Encounter between Chinese Medical Practices and Conventional Medicine in France and \\ Italy
}

\author{
LUCIA CANDELISE*
}

\begin{abstract}
This article is based on the results of comparative research into the appearance and integration of Chinese medicine (often limited to acupuncture in Europe) into French and Italian medical contexts during the twentieth century. The relationship between Chinese and conventional medicine and attempts at complementarity are studied, using as a starting-point a vast number of interviews with medical practitioners, observations of training sessions in the field, the study of the archives of the major French and Italian associations and schools of acupuncture and Chinese medicine, and a qualitative analysis of questionnaires distributed in training institutions. The motivations of French and Italian acupuncturists are also analysed, as are their representations of Chinese medicine. Particular attention is paid to a comparison between the French and Italian situations.
\end{abstract}

KEYWORDS: Acupuncture, moxibustion, Chinese medicine.

$\mathrm{T}$ he process of globalisation of Chinese medicine has unquestionably made the issues and initiatives involved in having it recognised as part of humanity's "intangible cultural heritage" all the more pressing.

An examination of the relationship between moves to have Chinese medicine inscribed on UNESCO's intangible heritage list and the globalisation of "traditional" medical knowledge also leads the question of how the two processes are being implemented. Without claiming to provide an exhaustive answer to this question, the aim of this article is firstly to show how some of the medical practices originating in China have been disseminated in two European countries, namely France and Italy. (1) Secondly, it presents the results of an analysis of the discourse of practitioners of these medical techniques in the two countries. These first-hand accounts, which make it possible to compare the situation in two different countries, demonstrate how this form of medical knowledge is being globalised and at the same time becoming a world heritage, albeit in terms of regional dynamics and rationales that are always very specific.

\section{Chinese medicine and globalisation}

Can it be said that Chinese medicine is a "globalised" body of knowledge and practice, or in other words, that its practice in the West is the fruit of a process of globalisation? Over the last ten years or so, a steadily increasing body of literature has appeared that deals with transnationalisation and globalisation of medical knowledge. This research frequently corresponds to contemporary thinking on medical pluralism and on the situation of non-conventional medicine in socio-cultural realities where biomedical knowledge predominates.

One of the first studies to deal with such subjects was Charles Leslie's Asian Medical Systems: A Comparative Study, ${ }^{(2)}$ published in 1976 and followed in 1992 by Paths to Asian Medical Knowledge, (3) co-edited by Charles Leslie and Allan Young, a collection of essays on the coexistence of several medical approaches (biomedicine and Chinese medicine in China, biomedicine and ayurvedic medicine in India) and the solutions adopted by health services in Asia to integrate the various health care traditions.
These works opened the door to many studies of the phenomenon of dissemination and circulation in Europe and America of these forms of medicine from the Far East. These studies include a book edited by Joseph Alter, Asian Medicine and Globalisation, (4) which examines the relationship between medicine and national cultural policy in China and India and the transnational movement of knowledge and people. Helle Johannessen and Imre Lázár's text ${ }^{(5)}$ also tackles the question of medical pluralism in several countries and continents (Hungary, Ghana, Germany, England, South Asia, Equator, Norway, and the Chiapas region). The issue of Anthropology \& Medicine edited by Erling Hóg and Elisabeth Hsu ${ }^{(6)}$ deals with the spread of Asian therapies to Tibet, Kazakhstan, Russia, the United States, Germany, Great Britain, and Tanzania. Mei Zhan's Other-worldly ${ }^{(7)}$ describes the various contexts and the different ways this knowledge and practice travels, demonstrating how the move engenders solutions and the construction of medical practices that are heavily influenced by the cultural and economic specificities of the place in which they appear. Marylène Lieber's article, recently published in the review Ethnic and Racial Studies, ${ }^{(8)}$ describes the

Lucia Candelise is a post-doctoral candidate working in the SPHERE laboratory (RESHEIS team, UMR 7219) in Paris and attached to the Lausanne University Institute of History of Medicine and Public Health. She defended her doctoral thesis at EHESS in Paris in joint supervision with the Università Milano Bicocca (luccicando@wanadoo.fr).

1. Our study specifically covers physicians trained in biomedicine who practice acupuncture. Therefore we do not take into account here the many other therapists and practitioners of Chinese medicine or those who encourage the practice of qigong and Chinese massage and who form networks that are relatively independent from those under study here.

2. Charles Leslie, Asian Medical Systems: A Comparative Study, Berkeley-Los Angeles, University California Press, 1976.

3. Charles Leslie and Allan Young, Paths to Asian Medical Knowledge, Berkeley-Los Angeles, University California Press, 1992

4. Joseph Alter (Ed.), Asian Medicine and Globalization, Philadelphia, University of Pennsylvania Press, 2005

5. Helle Johannesen and Imre Lázár (ed.), Multiple medical real time, patients and healers in biomedical, alternative and traditional medicine, vol. 4, Oxford, The EASA series, Bergahan Books, 2006.

6. Erling Høg and Elisabeth Hsu (ed.), Anthropology \& Medicine, Carfax Publishing, vol. 9, no. 3, 2002.

7. Mei Zhan, Other-worldly, Durham \& London, Duke University Press, 2009.

8. Lieber Marylène, "Practitioners of Traditional Chinese Medicine in Switzerland: Competing Justifications for Cultural Legitimacy," Ethnic and Racial Studies, (online version: July 2011, http://www.tandfonline.com/doi/ref/10.1080/01419870.2011.577227). 
consequences for the practice of Chinese medicine of recent Chinese immigration to Switzerland. The book edited by Laurent Pordié, Tibetan Medicine in the Contemporary World: Global Politics of Medical Knowledge and Practice ${ }^{(9)}$ highlights the link between tradition and globalisation, demonstrating the change in medical services in various national contexts as a result of neoliberal guiding principle and policies supporting biomedicalisation. All these studies highlight the fact that local knowledge (in our case Chinese) has entered a process of worldwide dissemination, and we should try to understand how this body of knowledge and its attendant practices become globalised. Moreover, the dynamics of the encounter and confrontation of Chinese medical knowledge with local medical knowledge as it is practiced in the European countries under study render the process of globalisation all the more complex by making it dependent (in its definition, reception, and practice) on the local realities into which it has been inserted.

The aim of this article is to examine how the globalisation process involved in the transportation of Chinese medicine from China to Europe can vary and take different forms depending on the social and national contexts of the countries concerned. It is a study of the dialogue between the local and the global, or rather between several local realities in a move towards the global.

It is possible to identify different domains of appropriation in the globalisation process. Indeed, globalisation is first and foremost played out in the territorial and geographical arena. It is also played out at the level of the content of the globalised object, matter, or knowledge. Since they trigger economic and technical repercussions, what are the results and the forms of knowledge or materials that are moved, transformed, and become international, and how do they acquire their value?

Globalisation can also be observed from a social point of view. What are the modalities and motivations behind a transnational and transcultural movement? What routes does it take? This third approach forms the basis of this article, which tackles the observation of clearly defined local realities (those of France and Italy) through an analysis of the discourse of French and Italian acupuncturists. This then leads to a preliminary examination of the relationship between the globalisation process and heritage initiatives.

\section{The field and research sources}

My work is based on the results of research begun in 2002 in France and Italy, the aim of which was to understand and describe the context surrounding the reception and institutionalisation of techniques from Chinese medicine in these two European countries. Work in the field was begun in places where these medical practices are taught. Two cities were chosen in each country: Paris and Strasbourg in France, and Milan and Bologna in Italy. The study draws its results from associations, private societies, and universities that teach Chinese medicine to western physicians, specialists and general medical practitioners. These teaching centres were the most favourable places in which to meet informed sources and the key figures in this medical story. The primary research sources were school archives and the publications of these societies and associations.

The research was built around an analysis of 43 interviews in Italy with medical acupuncturists, the managers of hospital departments where acupuncture and Chinese medicine are practised, and regional directors of projects to disseminate Chinese medicine. In France, 30 interviews were carried out with medical acupuncturists, physicians working with acupuncturists in hospital departments, and heads of departments interested in acupuncture. These were semi-structured interviews that followed Bernard Russell's methodological recommendations. ${ }^{(10)}$

The study also makes use of the results of a qualitative questionnaire distributed in three Italian schools (the So-wen school, Matteo Ricci, and MediCina), French schools that deliver inter-university diplomas in acupuncture and l'École Française d'Acupuncture. The questionnaires, filled in by physicians in their first, second, or third year of acupuncture studies were then subjected to qualitative analysis. The data from these questionnaires were analysed in accordance with Anselm Strauss's Grounded Theory. (11)

\section{The cases of France and Italy: An illustration of the practice of acupuncture and moxibustion in Europe}

When placing the question of globalisation in the dialogue between the global and the local, it was essential to use a local reality as a heuristic stool to shed light on the dissemination process of an exogenous medical technique within a European medical system. In addition, it was necessary to enlarge the scope of the research to several countries to illustrate from close range how these national realities vary in time, space, and quality, and the way in which practices and medical knowledge originating in China are received. This is why my research was carried out in two European countries, France and Italy. The comparative approach that characterises this research work was particularly important in understanding how and why the dissemination of Chinese medicine in Europe can be defined as a phenomenon of globalisation. The comparison between two national realities, France and Italy, and of two social contexts within which the dissemination process of Chinese medicine could be observed, highlighted the relationships between two different types of medicine within different local realities searching for a balance between confrontation and integration.

The results presented here concern the encounter between conventional and Chinese medicine over one century. The two Chinese techniques that have developed most fully in these two European countries are acupuncture and moxibustion. (12) Moreover, in France as in Italy, acupuncture is considered a medical act, ${ }^{(13)}$ which is intended to limit practitioners to those who have obtained a qualification in conventional medicine; in other words, general practitioners who have also had training in acupuncture or Chinese medicine. The practice of other health care techniques taken from Chinese medicine (pharmacopeia, gymnastics, and massage), which are

9. Laurent Pordié, Tibetan Medicine in the Contemporary World Global Politics of Medical Knowledge and Practice, London \& New York, Routledge, 2008.

10. Bernard H. Russell, Research methods in anthropology: Qualitative and quantitative approaches, Walnut Creek, Altamira Press, 2002 (3rd Edition).

11. See Barney Glaser and Anselm Strauss, The Discovery of Grounded Theory: Strategies for Qualitative Research, New York, Aldine, 1967; Anselm Strauss and Juliet Corbin, Basics of Qualitative Research: Grounded Theory Procedures and Techniques, Thousand Oaks, Sage, 1990; Anselm Strauss, La trame de la négociation: Sociologie qualitative et interactionnisme (The framework of negotiation: Qualitative sociology and interactionism), (texts collected and introduced by Isabelle Baszanger), Paris, L'Harmattan, 1992.

12. In future we will mention acupuncture without necessarily mentioning moxibustion, but it is both techniques, which are very often associated, that are intended.

13. In France, acupuncture has been considered a legal medical act since 1953, whilst in Italy it has only been so since 1989 . 
becoming increasingly widespread in all European countries, are still rarely present in conventional medical contexts (particularly in France). Practitioners of such therapies often form associations, schools, and independent medical networks and should be studied separately.

France and Italy are two examples of the much wider reality that is the West, taken in the widest sense of the term as encompassing all countries beyond the frontiers of China. They were chosen for specific reasons.

Firstly, France and Italy have been maintaining close ties in the teaching of the practice and theory of acupuncture. This special relationship has existed, moreover, for a good 20 years (between the 1970s and the 1990s).

It should also be noted that in both countries, the practice of Chinese medicine is almost exclusively limited to acupuncture and moxibustion. Indeed, for different reasons, it is only the placing of needles and the medical theory behind it that has really found its place and become popular in France and Italy. The Chinese pharmacopeia began to appear in training courses on Chinese medicine in Italy ten or so years ago and more recently in France as well, but massage and gymnastics are not widely studied and are practiced very little from a therapeutic point of view by medical acupuncturists.

\section{Acupuncture in French medical practice}

The presence of acupuncture in French medical practice dates back to the inter-war period of the first half of the twentieth century, mainly as a result of the work of George Soulié de Morant (1878-1955). George Soulié de Morant had been French Consul in China. Once back in Europe, encouraged by the interest of a circle of hospital physicians of the time, he became involved in the practice and transmission of Chinese acupuncture in France. His work remains a source of inspiration for medical acupuncturists even today. The network of physicians surrounding him then went on to create several societies and associations as well as a union of medical acupuncturists.

It is from 1943 onwards that acupuncture has been practiced and taught in private schools, which spread and multiplied throughout France. Starting in the early 1970s, this development went hand in hand with a considerable increase in the number of students (physicians interested in acupuncture). This period also corresponded to a vigorous attempt to have acupuncture accepted as a medical act on the part of French medical acupuncturists who were defending their practice and seeking to have it recognised and institutionalised. It was not until 1989 that inter-university diplomas in acupuncture, which replaced the training given in a certain number of private schools, were created in France, marking the official institutionalisation of the teaching of acupuncture. These diplomas have developed considerably in recent years, but we will not go into detail here. ${ }^{(14)}$

\section{"Traditionalist French acupuncture"}

In an article written in 2008, we examined the appearance of the practice of acupuncture in France by describing the route taken by French medical acupuncturists in defining their approach to Chinese medicine. ${ }^{(15)}$ We define this medical practice as "traditionalist French acupuncture," since it was the formulation of a medical theory originating in China then shaped and consolidated during the twentieth century in France. Its specific characteristics were based on the work of George Soulié de Morant, and later continued by French army physicians in Indochina. These physicians (who included Chamfrault, Huard, Cantoni, and Borsarello), attracted by what they saw as this "strange science," (16) devoted an enormous amount of energy to translating the classic texts of Chinese medicine. In fact, it was not simply a question of translation, but above all of reinterpretation, or even exegesis, of classic works on Chinese medicine by French physicians assisted by Chinese scholars. This approach to acupuncture was perpetuated and reinforced by the appearance in the 1960s of Dr. Nguyen Van Nghi, a Vietnamese acupuncturist also trained in conventional medicine. Dr. Nguyen Van Nghi was to expand the work of French medical acupuncturists by establishing this approach to acupuncture, which had partially taken shape in France before him.

This concept of acupuncture, defined here as "traditionalist" and specific to French physicians, is based on knowledge obtained from the translation of these classics of Chinese medical theory that are taken as a reference by French physicians in their practice. ${ }^{(17)}$ The process of translation and exegesis by French physicians (often with the help of Chinese scholars) involved a series of interpretations and reinterpretations of the principles of Chinese medicine. Moreover, this work is always done with reference to the so-called "Chinese tradition" and to a past that is valued all the more for being ancient and considered immutable (though removed from the context of its historic development). This question of being linked to a "tradition" has led us to think of it as an invented tradition, with reference to Hobsbawm and Ranger's idea of the invention of tradition. (18)

The interpretation and formal adoption of this knowledge has defined a coherent body of medical knowledge. Its coherence and above all its reference to a thousand-year old tradition act as a lever of legitimisation for those acupuncturist physicians who remain faithful to their traditionalist approach to acupuncture. Lastly, the tendency of this traditionalist approach to acupuncture is mainly to try to define this practice and the medical theory behind it as being "other" than conventional medicine.

Even today, this particular idea of acupuncture is defended by a great number of French medical acupuncturists who, whilst there are internal differences according to the various schools and masters, set themselves apart from the Italians and other European practitioners who use this knowledge and type of practice.

Other schools of thought and approaches to Chinese medicine and acupuncture developed in France after the 1990s. Certain French medical acupuncturists set out to seek proof through experimentation of the effectiveness of acupuncture by comparing these traditional practices with a far more "scientific" approach. Others were keen to expand their Chinese

14. See Éric Marié's article on the subject.

15. Lucia Candelise, "Construction, acculturation et diffusion de l'acupuncture traditionaliste française' au xxe siècle" (Construction, acculturation and dissemination of 'traditionalist French acupuncture' in the 20th century," Document pour une histoire des techniques (Document for a history of techniques), Paris, December 2008, pp. 76-88.

16. Albert Chamfrault, Traité de médecine Chinoise. Tome I, Acupuncture, moxas, massage, saignées (Treatise on Chinese Medicine, vol. 1, Acupuncture, moxas, massage, blood-letting), Angoulême, Coquemard, 1954, p. 7.

17. It should be noted that the expression "traditionalist French acupuncture" is used here to indicate the type of acupuncture that has been theorised and practised in France by a great number of medical acupuncturists. The idea of "traditionalist" that I put forward here concerns the type of acupuncture that claims to be part of a certain Chinese tradition, a tradition that has itself been constructed by these physicians. It is important to differentiate between practitioners who call themselves "traditional" and my definition of "traditionalism." I would like to thank the two anonymous China Perspectives evaluators for their remarks, one of whom drew my attention to the fact that the term "traditionalist" could lend itself to confusion. I use it to define a group of medical acupuncturists who call themselves "traditional." I would remind readers that this article does not deal with practitioners who are not physicians and who, it is true, could also claim to be "traditional."

18. We are referring here not only to Hobsbawn and Ranger's idea of the invention of tradition, but also to the work of Anthony Giddens. According to these authors, the invention of tradition is a process of formalisation and ritualisation characterised by references to the past. 
medical practice by creating academic courses, sometimes at university level, on the Chinese pharmacopeia.

\section{Acupuncture in Italy and its development from the 1970s onwards}

Thirty years later than in France, in the 1970s, an acupuncture clinic appeared in Italy. A Dr. Ulderico Lanza initiated the dissemination of the practice in the form in which it had been understood, formulated, and defended in France from the 1930s onwards. In 1968, Dr. Lanza, encouraged by Dr. Nguyen Van Nghi, founded the Scuola Italiana di Agopuntura and the Società Italiana di Agopuntura (S.I.A.). The work of spreading this therapeutic practice lay entirely before him, and these two organisations made an important contribution to this, the former by providing a training school for medical acupuncturists and the latter by creating an organisation charged with research, diffusion, and safeguarding of acupuncture in Italy, which still exists today.

Thanks to these two societies, Dr. Lanza began to initiate a dialogue between medical acupuncturists in France and those in Italy. Dr. Nguyen Van Nghi and Dr. Albert Gourion, for example, often gave seminars at the Scuola Italiana d'Agopuntura, as did Dr. Requena several years later.

Throughout the 1970s, other schools appeared in Italy, mainly in the north. Each of these schools is also a study and research centre for Chinese medicine and acupuncture. It should be noted that the teaching and research carried out in these centres is also inspired by the knowledge gained from "traditionalist French acupuncture." The French medical acupuncturists regularly invited to Italian schools are also the most recognised representatives of the traditionalist approach to acupuncture in France. Dr. Nugyen Van Nghi, Dr. Jean-Marc Kespi, Gilles Andrès, and Dr. Jean Schatz are regularly invited to the Italian schools as directors of studies or to teach.

\section{Italian acupuncture sets itself apart from traditionalist French acupuncture}

It was during the 1990s, 20 years after acupuncture's arrival, that Italian acupuncturists distanced themselves from French acupuncture, long taken as the one and only model. Many Italian schools and associations opened up to other models of Chinese medicine. More accurately, the work of Italian medical acupuncturists broke free of the French intellectual stranglehold to examine other national realities linked to Chinese medicine. In fact, contact with the English and North American world of Chinese medicine was made at almost the same time as with its country of origin, China.

The shift from a solely European source, i.e., medical knowledge built up in France, to a situation where knowledge was exchanged between several countries, took place in Italy in two almost simultaneous moves.

During the 1980s, several Italian physicians felt the need to extend their theoretical knowledge and clinical expertise beyond the domain of acupuncture. A growing interest in Chinese herbal medicine led these medical acupuncturists to contact British and American therapists, who understood and used Chinese herbs far better than French medical acupuncturists. Italian medical acupuncturists therefore went to Great Britain to attend seminars and train in Chinese herbal therapy. They forged working relationships with Giovanni Maciocia, an author, practitioner, and teacher in Great Britain who had built up useful relationships that included the Nanjing University of Traditional Medicine, and Ted Kaptchuk, an American practitioner, author, and pioneer of the integration of Chinese medicine in the West. At the same time, during the 1980s, China began to open up to the West. Improvements in the international political situation made it easier for Italian physicians and acupuncture schools to form direct relationships with China. At the beginning of the 1980s, several Italian physicians went to China to train in native traditional medicine. These same physicians were later to teach in Italian schools. At the same time, they maintained contact with Chinese physicians and universities (particularly Nanjing and Beijing), regularly inviting Chinese teachers to visit once or several times a year.

This Italian local reality was part of the much broader context of the abolition of national limits and the more widespread circulation of persons and knowledge at world level. It should be noted that it was from the 1990s onwards that globalisation came to the fore, and that this same period corresponds to an acceleration in the movement of players and knowledge, and of various attempts at the integration of Chinese medicine.

An example of this is the first decision by the World Health Organisation in 1989 to establish an international lexicon on the subject. The final decision taken in 1990 in Rome determined the lexicon for acupuncture points, putting forward, amongst others, a version in English. This WHO measure was followed by a series of regulatory measures on the practice and teaching of acupuncture and Chinese medicine.

\section{What does the practice of Chinese medicine mean for French and Italian physicians?}

Over and above developments in the elaboration of the knowledge and practice of Chinese medicine and in the history of its institutionalisation and legitimisation in France and Italy, it is interesting to analyse the discourse and experiences of the players, physicians, and practitioners involved in this medical practice. Such an approach can help us understand the expectations to which the introduction of Chinese medicine into European medical practice corresponded, the thinking of the physicians who approached it, and the form it took in the daily work of these twentiethcentury French and Italian practitioners. It also enables us to identify the mental framework and practical context in which some forms of Chinese therapy became an exogenous body of knowledge and a skill that could be integrated into national contexts other than that of its country of origin.

The answers of French and Italian physicians questioned on the reasons for their interest in Chinese medicine, the personal journey that led them to this medical practice, and the relationship that Chinese medicine might have with conventional medicine in their daily work, provided a wealth of information on the meaning of the presence of this medical practice in Europe. Their answers also shed light on the range of different visions that exist in the West regarding this body of knowledge and practice. The survey was fundamental to enabling us to make a relevant comparison between the situation in France and Italy.

\section{French medical acupuncturists oscillate between medical culture and exoticism: The choice of a narrative and ecological form of medicine}

The interviews we carried out reveal the different paths that led individual physicians to discover and study acupuncture. The paths were varied, but with elements that recur often in the responses of the French medical acupuncturists interviewed. Firstly, they were frequently left perplexed by 
their career in conventional medicine - often in hospitals - finding they were neither "satisfied" nor "convinced" by the way medicine is practiced and patients are taken care of. Looking for something different, they turned to acupuncture and sometimes to homeopathy and herbal medicine at the same time.

These physicians say they studied Chinese medicine to improve their medical practice, but also through personal interest with the aim of broadening their cultural horizons.

The personal accounts collected fully match the observations made by Anne Marcovich and Françoise Bouchayer in their work on acupuncture and "alternative" medical practices in France. (19) The two authors, having worked on this subject during the 1980s, confirm they observed a fairly marked rejection of conventional medicine on the part of the physicians they met.

In their responses, the physicians interviewed explained that they use the diagnostic methods of conventional medicine and prescribe the Western pharmacopeia fairly often, at the same time as practicing acupuncture. This "rejection" of allopathic medicine, less radical than that observed by the two authors 20 years previously, probably corresponds to the medical deontology of acupuncturists practicing in the 1990s and 2000s. These practitioners were probably influenced by the relationships between Chinese and conventional medicine established in other European countries (see Italy and the relationships between France and Italy on this subject), but also by the status of complementary and alternative medicine (CAM) in the United States ${ }^{(20)}$ and by all the research in this domain carried out by American research centres. Nonetheless, this more recent attitude towards conventional medicine does not prevent French medical acupuncturists from seeing acupuncture as "different" from allopathy. They do not envisage a relationship and theoretical integration between the two.

The position of French medical acupuncturists is close to Mike Saks's concept of a medical counter-culture. (21) They adopted a position in opposition to orthodox medicine because they were dissatisfied with their conventional medical training, did not totally subscribe to a rigorously scientific way of thinking as far as therapies are concerned, and had difficulty accepting their internship in hospital and the work done with patients in the public structures. All the medical acupuncturists interviewed criticised the rigidly determinist thinking of scientific medicine, rejected the idea of medical hyper-specialisation, and did not subscribe to the type of physician/patient relationship established in conventional medicine. (22)

The point of view taken by these medical acupuncturists corresponds, de facto, to the concept of postmodernity as defined by many sociologists of the late twentieth and early twenty-first century. (23) The positivist dogma of a form of medicine founded on certainties specific to biomedicine is called strongly into question here. Medical acupuncturists turn explicitly to a medical tradition, in other words, a traditional form of medicine that has broken away from the epistemology of conventional medicine. As Anthony Giddens ${ }^{(24)}$ and Ulrick Beck ${ }^{(25)}$ point out, modernity is in opposition to the idea of tradition, whilst a postmodern approach leads to a "revisiting" of traditions, as is the case in France with the establishment of a very definite style of acupuncture defined as "French traditionalist acupuncture." The medical tradition chosen by these physicians originated in China and comes from the Far East. They were therefore encountering a tradition other than the endogenous tradition of ancient Greco-Roman medicine.

The encounter with the "varied" and the "different," as we have seen in the responses of the French medical acupuncturists, echoes the analysis put forward by Ulf Hannerz, and taken up by Marc Abélès, (26) on the importance of diversity in a context of cultural globalisation.

The possibility of innovation and of an "alternative" that diversity can offer a clearly defined cultural context, of which the medical community is a segment, corresponds very well to the enthusiasm expressed by the medical acupuncturists interviewed. And it is true that the French medical acupuncturists expressed an almost miraculous feeling of surprise, amazement, and discovery in the face of this therapeutic practice so different from the conventional medicine in which all physicians are trained. Expressions used included "being amazed," "discovery of a new universe," "an opening up of man's vision," "something clicked," "very moved and... total commitment," "wonderment." These descriptions of the discovery of acupuncture through the teachings of a charismatic physician or through reading a text describe the approach to acupuncture experienced by these physicians very well. Acupuncture seems to have opened up a world of work on mankind and his diseases that the conventional medical approach could not give them.

What seems to have been extremely precious to all the medical acupuncturists interviewed is Chinese medicine's "global vision of humanity, which integrates the fact that man has a mind and a body and needs both of them." Man is seen as a body-mind unit that is part of nature and the universe, "a way of thinking that takes account of nature" and of natural phenomena: wind, heat, drought, humidity, etc.

For these physicians, originally trained in a mechanical vision of the way human beings function, their interest in acupuncture opens the door to a far wider vision of man and disease. In the words of Enzo Colombo and Paola Rebughini:

\section{What the dissemination of non-conventional therapies signals is the search for a new epistemology of disease, linked to the move from an idea of the body as a machine to that of the body as text,}

19. Anne Marcovich, Les représentations du corps et de la maladie chez les médecins acupuncteurs et chez leurs patients (Representations of the body and illness in medical acupuncturists and their patients), Paris, CNRS.INSERM.MIRE, 1987; Françoise Bouchayer, "Les voies du réenchantement professionnel" (Paths to professional reenchantment), in Pierre Aïach, Didier Fassin, Les métiers de la santé (The Health Professions), Paris, Anthropos, 1994, pp. 201-225.

20. Cf. Karen E. Adams, et al., "Ethical Considerations of Complementary and Alternative Medical Therapies in Conventional Medical Settings," Annals of Internal Medicine, vol. 137, no. 8, 15 October, 2002, pp. 660-664; David M. Eisenberg, "Advising Patients Who Seek Alternative Medical Therapies," Annals of Internal Medicine, vol. 127, no. 1, 1 July, 1997, pp. 61-69; Ted J. Kaptchuk, David M. Eisenberg, "Varieties of Healing. 1: Medical Pluralism in the United States," Annals of Internal Medicine, vol. 135, no. 3, 2001, pp. 189-195.

21. Cf. Mike Saks, Orthodox and Alternative medicine, London, Continuum, 2002, pp. 107-123.

22. On the subject of opposition to the medical establishment, see also Ivan Illich, "Némésis médicale. L'expropriation de la santé (Medical Nemesis: The expropriation of health," in F Fuvres complètes vol. 1, Paris, Fayard, 2005, pp. 583-786.

23. Cf. Bruno Latour, Nous n'avons jamais été modernes (We have never been modern), Paris, La Découverte, 1991; Anthony Giddens, Les conséquences de la modernité, Paris, L'Harmattan, 1994 (The consequences of Modernity, Oxford, Polity Press, 1990); Runaway World Globalisation in Reshaping our Lives, London, Profile Books, 1999; Zygmunt Bauman, La società dell'incertezza, Bologna, il Mulino, 1999; -- Il disagio della postmodernità, Milano, Bruno Mondadori, 2000; Ulrich Beck, La société du risque (The risk society). Paris, Flammarion, 2001 (Risikogesellscheft, Francfort, Suhrkamp Verlag, 1986); Alberto Melucci (ed.), La fine della modernità, Milan, Angelo Guerini, 1998; Ulf Hannerz, La diversità culturale, Bologne, II mulino, 2001, (tr. Transnational Connections: Culture, People, Places, London-New-York, Routledge, 1996); Marc Abélès, Anthropologie de la globalisation (Anthropology of globalisation), Paris, Payot, 2008

24. Anthony Giddens, op. cit., 1994, 2000.

25. Ulrich Beck, op. cit., 2001.

26. See Ulf Hannerz, op. cit., 2001; Marc Abélès, Anthropologie de la globalisation (Anthropology of Globalisation), Paris, Payot, 2008. Ulf Hannerz defines the process of the meeting of cultural diversities as a phenomenon of cultural "creolisation" and also as the "global ecumene." 
from the idea of illness as a mechanical event to that of a specific problem located in a unique context. ${ }^{(27)}$

For the non-conventional medical practitioners referred to by the authors, as for the medical acupuncturists interviewed, a new approach to disease and a new conceptual and narrative formulation of health problems ${ }^{(28)}$ appeared in the shape of Chinese medical theory. Chinese medical theory suggests to physicians trained in acupuncture a conception of disease understood more as a process than as a defined reality, or as "imbalance" rather than as a state necessarily induced by a specific physiological attack. Symptoms are therefore seen as expressions of living beings, and as such, as signs to be interpreted.

This way of thinking led these physicians to see the environment and the relationship between Man and his habitat differently and has led them to define acupuncture as an "ecological" medicine. (29) The relationship between microcosm and macrocosm in particular has been continuously stressed in their discourse.

In many of the accounts, the "philosophical" aspect is a determining factor in the discovery of Chinese medicine. Medical acupuncturists often tell of having been fascinated since their youth by the study of man and Western philosophy, as well as by the thinking and world of the Far East. On the one hand, fascination with a classical native way of thinking such as Greek philosophy (or sometimes by more contemporary philosophy) awakened in these physicians, dissatisfied with their mid-twentieth-century biomedical training, curiosity as to man and his position in the world. On the other hand, for the physicians interviewed, China and the Far East embodied an exotic way of thinking, and it is precisely this "exoticism" that was capable of bringing diversity to their medical practice. All this reminds us of Victor Segalen's definition of exoticism: ${ }^{(30)}$ the ability to conceive of "the other" or the idea of "other" and "different." These physicians seem to have been enriched and inspired by this same taste for exoticism that Victor Segalen describes. Acupuncturists, without necessarily having been to China, appropriate the instruments of different ways of thinking and different practices from those offered by the modern approach to medicine. This attitude also brings to mind Edward Said's concept of orientalism. ${ }^{(31)}$ Indeed, these medical acupuncturists certainly bring orientalism into their practice of acupuncture, since it has become for them the tangible, practical support for an intellectual investment and a "tradition of thinking, images, and language" that now constitute a reality and a presence in the West.

\section{Italian medical acupuncturists: Integration of two types of medicine}

Thanks to the results collected from meetings (interviews, questionnaires, and observations by the participants) with Italian medical acupuncturists, it has been possible to begin a comparison with the ideas of Chinese medicine expressed by the French physicians. In the analysis of interviews with French physicians, we examined concepts such as the recuperation of a tradition from a postmodern point of view, the rejection of conventional medicine made possible by the choice of a therapy that was "different" from orthodox medicine, and the place of exoticism in professional choice. Certain elements mentioned by the French physicians also appeared in the accounts given by the Italian physicians, but often seen from a different angle or as being less important to them than to the French physicians.
The Italian physicians, unlike their French counterparts, said first that they see acupuncture as integrated with, or complementary to, conventional medicine. They also said they see the practice of acupuncture as an alternative to or with orthodox medicine.

Certain Italian medical acupuncturists were drawn to Chinese medicine through their attraction to its philosophy, symbolism, or esotericism. Certainly, the attraction for the Eastern model and the fascination with orientalism were also among the elements that motivated them to explore Chinese medicine. However, the attitude of the Italian physicians seems very different from that of French physicians who were driven by the desire to expand their cultural horizons through knowledge of the Chinese world.

They perceived Chinese thinking as a subjective experience linked to precise sensations and consequently involving a significant physical dimension. They integrated a Chinese medical practice into their own work after having personally experienced and experimented with physical activities such as martial arts or massage. This represents a process of "embodiment" ("existential ground of culture and self ") (32) as described and presented by Thomas J. Csordas.

Let us take the case of a gynaecologist who through dance discovered aikido and acupuncture. It is clear that for him, the mechanism of growing awareness and recognition ("existential ground") of different ways of perceiving the body were activated through his own physical and sensory experiences. He states that he understood the workings of his own body through dance and that he then transposed this knowledge into his medical practice. To find some coherence between the two worlds (the feelings he experienced and his work as a physician), this gynaecologist chose to study and practice Chinese medicine and gave the following explanation for his choice: "I was interested in a type of medicine that worked on energy." This physician therefore explored the approach of Chinese medicine that worked "on energy" and that was different from the specialised medicine he practiced in his hospital work.

In the responses from the Italian medical acupuncturists interviewed, Chinese medicine is very often seen as more all-encompassing than just acupuncture. In fact, the practice of Chinese medicine in Italy is

27. Enzo Colombo, Paola Rebughini, La medicina che cambia, Bologna, Il Mulino, 2003, p. 50.

28. On the subject of the importance of narrative in the therapeutic process and in the construction of medical discourse, see the authors of the Harvard Medical School: Arthur Kleinman, The illness narratives: Suffering, healing, and the human condition, New York, Basic Book, 1988; Byron Cood Comment faire de l'anthropologie médicale, Médecine, rationalité et vécu, traduit de l'anglais par Gleize S. (original title: Medicine, Rationality and Experience), Le Plessis-Robinson, Institut Synthélabo, 1998. See also Linda Garro and Cheryl Mattingly, Narrative and the cultural construction of illness and healing, Los Angeles, University of California Press, 2000.

29. On this subject, Cf: Kristoffer Schipper, "Écologie taoïste: la transformation intérieure" (Taoist ecology: The interior transformation), in La religion de la Chine (The Religion of China), Paris, Fayard, 2008, pp. 161-178. See also Paul Unchuld, "The social Organization an Ecology of Medical Practice in Taiwan," in Leslie Charles, Asian medical systems: A comparative study, London, University of California Press, 1976, pp. 300-321.

30. "...strip the word 'exoticism' of its exclusively tropical, exclusively geographical meaning. [...] And then quickly define, set down the sensation of Exoticism, which is nothing other than the notion of the different; the perception of the diverse; the knowledge that something is not oneself; and the power of Exoticism, which is nothing but the power of conceiving otherwise." (Victor Segalen, Essay on Exoticism, Cognac, Bibliothèque artistique et littéraire, 1994, p. 23). "Far from stifling it, the sensation of Exoticism enhances and enriches one's personality. The capacity to discriminate is formed through the sensation of diversity. Those who are capable of tasting it are strengthened, enhanced," (Victor Segalen, ibidem, p. 49).

31. "Orientalism, therefore, is not an airy European fantasy about the Orient, but a created body of theory and practice in which, for many generations, there has been a considerable material investment" (Edward W. Said, Orentalism, New-York, Vintage Books, 1979, pp. 5-6).

32. Thomas Csordas (Ed.), Embodiment and Experience, Cambridge, Cambridge University Press, 1994, p. 4. See also by the same author, "Embodiment as a Paradigm for Anthropology," Ethos, no. 18, 1990, pp. 5-47. 
not necessarily limited to acupuncture, but is considered, taught, and often practiced as a form of medicine that has a theoretical base and several therapeutic applications that include acupuncture but also herbal medicine or the pharmacopeia, massage, and gymnastics.

What is revealed in the interviews with Italian physicians is the complexity of the different kinds of therapy available, some of which come from Chinese medicine and others from conventional medicine.

For most of the Italian physicians, the description of their training starts with a course in acupuncture taken at a private Italian school. Interest in Chinese herbal medicine only appears later, once they have finished their training in acupuncture and probably once they have assimilated the practice and medical theory. This is how certain Italian medical acupuncturists become "Chinese" physicians, using not only needles but also prescriptions for Chinese herbs in their practice. Rare are those who also perform massage, but on the other hand, several are seriously interested in qigong, to the point of using it as a tool in their own surgeries.

However, none of these physicians, whether they practice only acupuncture or also other techniques drawn from Chinese medicine, abandon their training in conventional medicine and are not at all opposed to it. Italian medical acupuncturists defend their role as physicians, having trained in both biomedicine and Chinese medicine.

The relationship established between conventional medicine and Chinese medicine in the work of these physicians is a question of boundary work, of the demarcation between two approaches to the care of patients and to disease.

The description of the relationship between non-conventional physicians and orthodox medicine has been the subject of several research projects. Sarah Cant and Ursula Sharma, ${ }^{(33)}$ for example, examine the difficulty of defining how non-conventional medicine can be integrated into the practice of conventional physicians attracted by these alternative therapies. It entails examining at close-range the place occupied by the body of knowledge belonging to conventional medicine and that occupied by the body of knowledge belonging to Chinese medicine. Does one body of knowledge prevail?

Enzo Colombo and Paola Rebughini define integrated medicine as a "medical metaspace," (34) and therefore a dimension that transcends simply paying attention to the physical pathology (disease) to include improving the conditions of patient care and treatment. The authors take a definition of health given by the WHO in 1946. ${ }^{(35)}$

In her introduction to Multiple Medical Realities, Helle Johannessen (36) examines the relationship between different practices and medical theories (medical pluralism). She takes as a starting point the three bodies (individual, social, and political) described by Margaret Lock and Nancy Scheper-Hughes ${ }^{(37)}$ and maintains that medical pluralism finds concrete expression in the form of a network that is both the fruit of these three corporal dimensions and the cement that binds them. This means that this network is present at the level of both knowledge and practice (praxis), allowing the move from one medical dimension to another without rigidity or contradictions (open networks based on elective affinity).

Anne Marcovich, in her book Les représentations du corps et de la maladie chez les médecins acupuncteurs et chez leurs patients (The representations of Medical acupuncturists and their patients with regard to the body and disease) ${ }^{(38)}$ states:
... the problem of translating Chinese concepts in the West comes into its own here, giving full substance to the idea of the "cobbling together" of concepts by history. But the idea of translation extends beyond the simple problem of language. [...] The mode in which [medical acupuncturists] function is not the mixture or cobbling together of two models, but the move from one to the other, the translation [...] of the one into the other, a little like the way bilingual people pass from one language to the other without mixing them up. ${ }^{(39)}$

Anne Marcovich's idea of the passage from one model of medical thought to another, and that of the "translation" of one medical concept to another that each physician performs when faced with a patient and for each consultation, intervention, and decision, corresponds very well to the representations, work, and subjective experience of physicians who integrate Chinese medicine into their therapeutic work. The comparison with bilingualism seems to provide an excellent explanation of this move from one body of knowledge to another.

The balance between the two forms of knowledge, the two health care techniques, and the two descriptions of the workings of the body and of life is created individually by each physician, depending on his own experience, capacity of integration, and intuition. Lastly, it is a question of the "synergy" between the two types of knowledge and two medical practices that does not imply a mixture of the two methods, but simultaneous action with a view to obtaining a better result, better care, and possibly better healing.

\section{Conclusion}

We have presented the general context of the appearance and reception of acupuncture in two European countries (mentioning in passing several other health care techniques also taken from Chinese medicine). We would define these movements as a transnational and globalisation process. We understand this idea of globalisation as the relationship of the global (Chinese knowledge and medical know-how that is becoming globalised by moving from China to other countries) and the local (the understanding and re-elaboration of the body of knowledge within national realities and within different professional communities). We have insisted in particular on the conception French and Italian practitioners have of Chinese medicine to show how, in two different national realities, this type of medicine takes on specific forms of appropriation and how it responds to the particular requirements - cultural as well as professional - of each social context, resulting in a metamorphosis of Chinese medicine.

33. Cf. Sarah Cant, Ursula Sharma, A New Medical Pluralism, London, Routledge, 1999, pp. 172-176.

34. Enzo Colombo, Paola Rebughini, La medicina contesa, Roma, Carrocci, 2006, p. 78.

35. "Health is a state of complete physical, mental and social wellbeing, and not merely the absence of disease or infirmity."

36. Helle Johannessen, Irme Lázár, Multiple Medical Realities, New-York, Berghahn Books, 2006.

37. Margaret Lock, Nancy Scheper-Hughes, "A Critical-interpretative Approach in Medical Anthropology: Rituals and Routines of Discipline and Dissent," Medical Anthropology, Contemporary Theory and Method, Westport, Praeger Publishers, 1990, pp. 47-72.

38. Anne Marcovich, Les représentations du corps et de la maladie chez les médecins acupuncteurs et chez leurs patients (The representations of Medical acupuncturists and their patients with regard to the body and disease), Paris, CNRS.INSERM.MIRE, 1987.

39. Anne Marcovich, ibid., p. 100. 
We would like, by way of a conclusion, to offer several remarks concerning the relationship that exists between this process and initiatives to have Chinese medicine declared a World Heritage. These remain open questions rather than real answers.

At the beginning of the 2000s, UNESCO set up a major project for the safeguarding of intangible cultural heritage, and in 2010, acupuncture and moxibustion were inscribed on its representative list. ${ }^{(40)}$

Following this institutionalisation of the cultural heritage relating to Chinese medicine, we would observe, first of all, that amongst the different types of treatment offered by Chinese medicine, the only techniques inscribed on the safeguard list to date are acupuncture and moxibustion. We have also seen that these are the two techniques that have spread most widely in the West, or at least in France and Italy.

There undoubtedly exists a relationship between the choice to inscribe acupuncture and moxibustion on UNESCO's list and the phenomenon of the dissemination and globalisation of Chinese medicine previously discussed.

Noriko Aikawa-Faure, in her introductory text to the UNESCO Convention for the safeguard of intangible cultural heritages states:
The urgency of safeguarding has been felt all the more urgently since the international community has explicitly begun to be concerned by the damaging consequences of globalisation. This idea distinguishes intangible heritage from tangible heritage. (41)

As far as medicine is concerned, this heritage initiative on the part of the Chinese government is certainly not unrelated to the globalisation of this "national heritage." It remains to be seen whether the globalisation of Chinese medicine is viewed by China as a "damaging consequence" or as an instrument of social and economic exchange with the world that lies beyond its frontiers. But it would also be interesting to understand more fully how the appropriation of Chinese medicine by medical practitioners in other countries, dating back almost a century, is influencing the role it plays in the political affairs of its country of origin.

\section{Translated by Elizabeth Guill}

. "Acupuncture and Moxibustion of traditional Chinese medicine" inscribed on the representative list of Humanity's Intangible Cultural Heritage: http://www.unesco.org/culture/ich/index.php?lg= en\&pg=00011\&RL=00425 (consulted on 23 November 2011).

41. Noriko Aikawa-Faure, "The UNESCO Convention for the safeguarding of the intangible cultural heritage and its implementation," in Le patrimoine culturel immatériel à la lumière de l'Extrême-Orient (Intangible Cultural Heritage in the light of the Far East), International de l'imaginaire, no. 24, Acte Sud, 2009, p. 28. 